\section{Anemia e ferropenia em gestantes: dissensos de resultados de um estudo transversal*}

\section{Anemia and iron deficiency in pregnant women: disagreements among the results of a cross-sectional study}

Cristiane Campello Bresani Ariani Impieri de Souza ${ }^{1,2}$ Malaquias Batista Filho ${ }^{1,2}$ José Natal Figueiroa ${ }^{1,2}$

1 Departamento de Pesquisa. Instituto Materno Infantil Prof Fernando Figueira-IMIP. Rua dos Coelhos, 300. Recife, PE, Brasil. CEP: 50.070-550. E-mail: crisbresani@terra.com.br

2 Pós-Graduação. Instituto Materno Infantil de Pernambuco-IMIP Recife, PE, Brasil.

\section{Abstract}

Objectives: to describe the frequency of anemia and iron deficiency anemia, using two cutoff points for hemoglobin concentration $(\mathrm{Hb})$ as well as serum ferritin levels in women with low-risk pregnancies.

Methods: a cross-sectional study was carried out based on the database records of 318 pregnant women at the Instituto Materno Infantil Professor Fernando Figueira-IMIP, in the city of Recife, State of Pernambuco, Brazil, between May 2000 and June 2001. The frequency of anemia and/or iron deficiency anemia were determined using two Hb cutoff points $(<11.0$ and $<10.5 \mathrm{~g} / \mathrm{dL}$ ) in addition to serum ferritin levels. Data were analyzed using the Epi-Info 6.04b and Minitab v.14.2 software programs. The project was approved by the Research Ethics Committee.

Results: the frequency of anemia $(\mathrm{Hb}<11.0 \mathrm{~g} / \mathrm{dL})$ and the frequency of iron deficiency anemia $(\mathrm{Hb}<11.0 \mathrm{~g} / \mathrm{dL} ;$ ferritin $<12 \mathrm{ng} / \mathrm{mL})$ were $56.6 \%$ and $10.7 \%$, respectively. When the $H b$ cutoff point was changed to $10.5 \mathrm{~g} / \mathrm{dL}$, the frequency of anemia fell to $37.4 \%$ and the frequency of iron deficiency anemia to 7.9\%. Higher serum ferritin levels were found in anemic patients than in non-anemic patients, regardless of the $\mathrm{Hb}$ cutoff point used.

Conclusions: the frequency of anemia was acceptable, but the proportion of iron deficiency anemia was far lower than expected. Ferritin levels seemed to behave in a way that contradicts the theoretical literature on the subject.

Key words Anemia, ferritins, Pregnancy

\section{Resumo}

Objetivos: descrever as freqüências de anemia e ferropenia em gestantes de baixo risco, de acordo com a ferritina sérica e diferentes pontos de corte da concentração de hemoglobina $(\mathrm{Hb})$.

Métodos: estudo transversal, utilizando-se banco de dados com 318 gestantes atendidas no período de maio de 2000 a junho de 2001, no Instituto Materno Infantil Prof. Fernando Figueira-IMIP, em Recife, Pernambuco. Determinou-se a freqüência de anemia elou ferropenia em função da ferritina e dois diferentes pontos de corte da $\mathrm{Hb}(11,0$ e $10,5 \mathrm{~g} / \mathrm{dL})$. Os dados foram analisados nos programas Epi-Info 6.04b e Minitab v.14.2. O projeto foi aprovado pelo Comitê de Ética em Pesquisa do IMIP.

Resultados: as freqüências de anemia $(\mathrm{Hb}<11,0 \mathrm{~g} / \mathrm{dL})$ e anemia ferropriva $(\mathrm{Hb}<11,0 \mathrm{~g} / \mathrm{dL}$; ferritina $<12 \mathrm{ng} / \mathrm{mL}$ ) foram $56,6 \%$ e $10,7 \%$, respectivamente. Mudando o ponto de corte da $\mathrm{Hb}$ $(<10,5 \mathrm{~g} / \mathrm{dL})$, a freqüência de anemia foi reduzida para $37,4 \%$ e de anemia ferropriva para $7,9 \%$. Os valores de ferritina sérica foram maiores nas anêmicas do que nas não anêmicas, independente do ponto de corte de $\mathrm{Hb}$ considerado na definição da anemia.

Conclusões: a freqüência de anemia na amostra foi compatível com o esperado, porém, a proporção de anemia ferropriva foi muito aquém. Os valores de ferritina se comportaram de maneira inversa ao que teoricamente, era esperado.

Palavras-chave Anemia ferropriva, Ferritinas, Gravidez

Estudo baseado em banco de dados secundário de um ensaio clínico publicado na Revista Panamericana de Salud Pública (Souza AI de, Batista Filho M, Ferreira LOC, Figueirôa JN. Efetividade de três esquemas com sulfato ferroso para tratamento de anemia em gestantes. Rev Panam Salud Pública. 2004; 15: 313-9). 


\section{Introdução}

O grupo de mulheres no ciclo grávido-puerperal ainda hoje expressa altos índices de anemia, mesmo após as recomendações da Organização Mundial de Saúde (OMS) de suplementação universal nesse estrato populacional. ${ }^{1,2}$ Há evidências de que a anemia no ciclo gestatório, especialmente por carência de ferro, pode estar associada a aumento de mortalidade materna e perinatal, prematuridade, baixo peso ao nascer e morbidade do infante. ${ }^{1,3-6}$

Define-se laboratorialmente anemia na gestação como a queda de mais de dois desvios-padrão abaixo da média dos valores da concentração de hemoglobina (Hb) e/ou hematócrito. ${ }^{7}$ Sob um prisma funcional, pode ser vista como a inabilidade do eritron em manter a fisiologia da gravidez. ${ }^{8}$ Outra maneira, seria definir anemia e seus padrões laboratoriais de acordo com os níveis que influenciassem a saúde da mãe e da criança. ${ }^{9}$ Não há, portanto, consenso na definição dessa doença na gestação. Mesmo do ponto de vista laboratorial, os pontos de corte adotados para a hemoglobina são variáveis. Alguns autores levam em consideração a fisiologia da gravidez, considerando-os mais baixos (10,0 a $10,5 \mathrm{~g} / \mathrm{dL}$ ) para o segundo trimestre, tendo em vista a hemodiluição desse período. ${ }^{10,11}$ Já o critério da $\mathrm{WHO}^{1}$ utiliza a $\mathrm{Hb}$ abaixo de $11,0 \mathrm{~g} / \mathrm{dL}$ independente do trimestre gestacional.

Por sua vez, os valores de ferritina se elevam no primeiro trimestre e, posteriormente, sofrem queda fisilógica de 30 a $50 \%$ no segundo trimestre, atingindo valores abaixo dos pré-gravídicos, devido à hemodiluição e ao aumento da demanda do ferro. ${ }^{12-19}$ Contudo, a ferritina manteria sua correlação com os estoques de ferro, sendo correntemente considerada o melhor parâmetro para inferir o grau de deficiência de ferro e, teoricamente, quando associada à redução da hemoglobina, o diagnóstico definitivo de anemia ferropriva na gravidez. ${ }^{12,13}$ Por outro lado, gestantes usualmente possuem valores de ferritina próximos ou na faixa da depleção, sem implicarem em privação funcional de ferro, sendo, portanto, seu ponto de corte também variável (10,0 e $30,0 \mathrm{ng} / \mathrm{mL})$. $^{1,4,20}$

A carência de ferro é classicamente considerada a principal responsável pelos casos de anemia em populações de pobres condições socioeconômicas, inclusive na gestação. ${ }^{1,21}$ Dessa forma, a prevalência geral de anemia é comumente utilizada como proxi da anemia ferropriva e a prevalência estimada de deficiência de ferro situar-se-ia em torno de 2,5 vezes ou mais a de anemia ferropriva numa dada população com alta prevalência de anemia $(\geq 40 \%)$. $^{1,2}$

Estima-se que quase a metade das mulheres grávidas no mundo seria anêmica, sendo $52 \%$ em países "não industrializados". Informes da Organização Pan-Americana da Saúde indicam que $42 \%$ das gestantes no Brasil seriam anêmicas. ${ }^{1,22}$ Estima-se, no Nordeste brasileiro, entre $30 \%$ e $40 \%$ de anemia no ciclo gravídico. ${ }^{21}$ Não há na literatura prevalência definida de anemia na gestação para o estado de Pernambuco, embora dois trabalhos tenham revelado frequiências de $36 \%$ e $42 \%$ no momento do parto. ${ }^{23,24}$

Focalizando-se a deficiência de ferro na gestação, evidencia-se que não há dados consolidados em nível global. ${ }^{6}$ Mas, recorrendo-se à utilização da anemia como indicador indireto, poderse-ia prever que a grande maioria das mulheres grávidas nas nações subdesenvolvidas e quase $60 \%$ nos países desenvolvidos seriam ferropênicas. ${ }^{1}$

A despeito do maior risco teórico de anemia ferropriva na gravidez, perduram inúmeras indefinições no que diz respeito à distribuição do problema e de seus fatores etiológicos nas populações e à lógica das recomendações de controle direcionadas genericamente à carência de ferro. Daí a relevância e o objetivo de investigar se os baixos níveis de $\mathrm{Hb}$ correspondem de fato à condição de anemia ferropriva na gravidez.

\section{Métodos}

Foram recrutadas, por um processo de amostragem por conveniência entre os anos de 2000 e 2001, gestantes que se apresentaram ao Ambulatório de Pré-Natal do Centro de Atenção à Mulher do Instituto Materno Infantil Prof. Fernando Figueira (IMIP), em Recife, Pernambuco. Foram eleitas 318 mulheres com 16 a 20 semanas de gestação de baixo risco e com dosagens de $\mathrm{Hb}$ sangüínea e de ferritina sérica, obtidas no momento do ingresso no estudo. Foram excluídas as gestantes que utilizavam medicamentos contendo ferro.

A idade gestacional foi verificada pela data da última menstruação e confirmada por estimação ultra-sonográfica. Baixo risco obstétrico foi definido como gestação única e ausência de doenças conhecidas previamente à gestação. Considerou-se anemia em dois pontos de corte, quando $\mathrm{Hb}$ abaixo de $11,0 \mathrm{~g} / \mathrm{dL}$ ou $10,5 \mathrm{~g} / \mathrm{dL}$, e ferropenia quando ferritina sérica abaixo de $12 \mathrm{ng} / \mathrm{mL}$. A Hb foi mensurada por contador automático tipo Coulter (modelo $\mathrm{T}$ 890) e a ferritina sérica (ferritina-S) foi mensurada pelo método de enzimaimunoensaio Cobas ${ }^{\circledR}$ Core 
Ferritin EIA Roche ${ }^{\circledR}$.

O tamanho amostral foi calculado pelo ensaio clínico que deu origiem ao banco de dados aqui utilizado, visando detectar a diferença de $0,5 \mathrm{~g} / \mathrm{dL}$ nos valores de $\mathrm{Hb}$ em resposta à intervenção aplicada, segundo a fórmula de Kirkwood com erro de 0,05 , poder de 0,80 e variâncias de $0,80 .{ }^{25}$ Foram obtidas as distribuições de freqüências e medidas de tendência central e de dispersão das variáveis. Para a diferença de medianas, foi utilizado o teste de MannWhitney e considerado nível de significância de $5 \%$. Os dados foram analisados com os programas EpiInfo versão $6.04 \mathrm{~b}$ e Minitab v.14.2. O projeto foi aprovado pelo Comitê de Ética em Pesquisa da Instituição onde se desenvolveu.

\section{Resultados}

Observa-se, na Tabela 1, onde se considerou o ponto de corte de $\mathrm{Hb}<11 \mathrm{~g} / \mathrm{dL}$, que das 318 mulheres incluídas no estudo, 17,6\% tinham ferropenia, sendo $6,9 \%$ não anêmicas e $10,7 \%$ anêmicas. Do total das participantes, $56,6 \%$ eram anêmicas, sendo $45,9 \%$ representados por anêmicas sem ferropenia.

A Tabela 2 expõe que, utilizando-se o ponto de corte de $10,5 \mathrm{~g} / \mathrm{dL}$ para a $\mathrm{Hb}$, a freqüência de anemia reduziu-se para $37,5 \%$, sendo $7,9 \%$ de anemia ferropriva e $29,6 \%$ de anemia sem ferropenia.

A mediana dos valores de ferritina sérica foi maior entre as anêmicas $(39,3 \mathrm{ng} / \mathrm{dL})$ que entre as não anêmicas $(29,2 \mathrm{ng} / \mathrm{dL})$, mostrando uma diferença

Tabela 1

Distribuição de freqüências de anemia $(\mathrm{Hb}<11,0 \mathrm{~g} / \mathrm{dL}$ ) e/ou ferropenia (ferritina $<12,0 \mathrm{ng} / \mathrm{mL}$ ) entre 318 gestantes de baixo-risco. Recife, Pernambuco, Instituto Materno Infantil Prof. Fernando Figueira-IMIP, 2000-2001.

\begin{tabular}{lcc}
\hline Classificação hematológica & N & $\%$ \\
\hline Ferropênicas não anêmicas & 22 & 6,9 \\
Ferropênicas anêmicas & 34 & 10,7 \\
Não ferropênicas anêmicas & 146 & 45,9 \\
Não ferropênicas não anêmicas & 116 & 36,5 \\
Total & 318 & 100,0 \\
\hline
\end{tabular}

Tabela 2

Distribuição de freqüências de anemia $(\mathrm{Hb}<10,5 \mathrm{~g} / \mathrm{dL}$ ) e/ou ferropenia (ferritina $<12,0 \mathrm{ng} / \mathrm{mL}$ ) entre 318 gestantes de baixo-risco. Recife, Pernambuco, Instituto Materno Infantil Prof. Fernando Figueira-IMIP, 2000-2001.

\begin{tabular}{lcc}
\hline Classificação hematológica & N & $\%$ \\
\hline Ferropênicas não anêmicas & 31 & 9,7 \\
Ferropênicas anêmicas & 25 & 7,9 \\
Não ferropênicas anêmicas & 94 & 29,6 \\
Não ferropênicas não anêmicas & 168 & 52,8 \\
Total & 318 & 100,0 \\
\hline
\end{tabular}


estatisticamente significativa $(p=0,040)$. A ferritina também foi maior nas anêmicas ao mudar o ponto de corte da $\mathrm{Hb}$ para $10,5 \mathrm{~g} / \mathrm{dL}$, mantendo a mesma diferença, mas sem significância estatística $(p=0,283)$, como se observa na Tabela 3.

\section{Discussão}

Embora o propósito aqui não seja de representação epidemiológica do problema, o tamanho e aleatoriedade da amostra e a utilização de métodos automáticos de eritrometria apontam para a validade do estudo, em especial os achados desse enfoque específico, mais voltado aos discensos internos encontrados, a fim de levantar questões e instigar o pesquizador ao tema das anemias na gravidez.

A frequiência de anemia encontrada, ao se utilizar o critério da OMS, ${ }^{1}$ foi superior à estimada para o Brasil, segundo relatório da OPAS de $2003^{22}$ (42\% das gestantes) e compatível com o esperado para as nações em desenvolvimento, segundo a OMS, em $2001^{1}$ (52\% das gestantes), situando-se na condição classificada como grave em escala epidemiológica $(\geq 40 \%)$, inclusive superando às encontradas nos ainda escassos estudos brasileiros que se ocuparam do assunto. ${ }^{1,23,24,26,27}$ Ao se utilizar um critério menos rígido para o limite inferior da $\mathrm{Hb}(10,5 \mathrm{~g} / \mathrm{dL})$, verificou-se uma freqüência ainda muito próxima da gravidade epidemiológica, de quase $40 \%{ }^{1}$

Entende-se que a anemia ferropriva é o resultado de uma evolução por estágios sucessivos de deficiência de ferro até que se instale o deficit de hemoglobina, daí os conceitos da OMS, que sugerem a anemia como um proxi de anemia ferropriva e essa como um estimador da prevalência geral de ferropenia em populações que não tenham outro determinante importante de anemia. ${ }^{1,28}$ No entanto, os dados encontrados contrariam essa lógica sob o ponto de vista epidemiológico.

Ressalta-se que quase a metade da população estudada foi classificada como anêmica sem ferropenia e que os $10,7 \%$ de anemia ferropriva na amostra total significam, na verdade, menos de $20 \%$ de anemia atribuível à ferropenia. Ou seja, as proporções foram muito aquém do que se teoriza para uma população que teria risco bastante elevado de carência de ferro: gestantes de uma região pobre em um país em desenvolvimento. ${ }^{1,22}$ Por sua vez, a freqüência de ferropenia com e sem anemia também se mostrou abaixo do esperado $(17,6 \%)$; uma vez que deveria representar pelo menos 2,5 vezes a freqüência de anemia ferropriva. ${ }^{1}$

Quando se utilizou o ponto de corte mais baixo para a $\mathrm{Hb}$, as superposições entre valores baixos de $\mathrm{Hb}$ e de ferritina mantiveram-se não compatíveis com os conceitos vigentes, embora que em menor escala. Ocorreu novamente uma grande proporção de anêmicas com ferritina considerada normal, e se repetiram desproporções entre anemia ferropriva e total de anemia (20\%) e entre anemia ferropriva e o total de ferropenia (2,2 vezes). Surgem então divergências

Tabela 3

Valores da ferritina sérica (ferritina-S) entre anêmicas e não anêmicas de acordo com dois pontos de corte para a hemoglobina, entre 318 gestantes de baixo-risco. Recife, Pernambuco, Instituto Materno Infantil Prof. Fernando Figueira-IMIP, 2000-2001.

\begin{tabular}{|c|c|c|c|c|c|c|}
\hline \multirow[b]{2}{*}{ Parâmetro } & \multicolumn{2}{|c|}{ Anêmicas } & \multicolumn{2}{|c|}{ Não anêmicas } & \multirow[b]{2}{*}{ IC95\%* } & \multirow[b]{2}{*}{$P^{* *}$} \\
\hline & $\mathrm{n}$ & mediana & $\mathrm{n}$ & mediana & & \\
\hline \multirow[t]{3}{*}{ Ferritina-S (ng/mL) } & 180 & 39,3 & 138 & 29,2 & $-29,3-4,6$ & 0,040 \\
\hline & \multicolumn{2}{|c|}{$\mathrm{Hb}<10,5$} & \multicolumn{2}{|c|}{$\mathrm{Hb} \geq 10,5 \mathrm{~g} / \mathrm{dL}$} & & \\
\hline & $\mathrm{n}$ & mediana & $\mathrm{n}$ & mediana & IC95\%** & $\mathrm{P}^{* *}$ \\
\hline Ferritina-S (ng/mL) & 119 & 42,8 & 199 & 32,3 & $-3,0-11,6$ & 0,284 \\
\hline
\end{tabular}

*IC95\%=intervalo de confiança de $95 \%$ para a diferença de medianas; ${ }^{*}$ Teste de Mann-Whitney. 
bem evidentes, entre o que seria a prevalência esperada de deficiência de ferro e de anemia ferropriva e as cifras realmente encontradas no conjunto amostral, mesmo de acordo com o sugerido mais recentemente pelo Global Burden of Disease 2000 Project, que já assume $50 \%$, e não a grande maioria das anemias, como atribuíveis à deficiência de ferro em termos globais. ${ }^{6}$

Tem-se, portanto, um impasse com duas possíveis alternativas. A primeira seria que, para populações com baixos índices de desenvolvimento, incluindo a subpopulação de gestantes, a etiologia das anemias seria mais diversificada (ferropenia, doenças crônicas, doenças endêmicas, hemoglobinopatias e diferenças raciais). ${ }^{1}$ A outra alternativa seria pôr em dúvida os pontos de corte da $\mathrm{Hb}$ e/ou da ferritina sérica correntemente utilizados na gravidez, que poderiam estar superestimando a ocorrência de anemia e/ou subestimando a carência de ferro, respectivamente.

Como assinalado por Santos, ${ }^{26}$ em 2002, a literatura brasileira sobre anemia, além de escassa, não define a real prevalência e etiologia das anemias na nossa população, incluindo a de gestantes.

Alguns estudos asiáticos, europeus e norte-americanos, que avaliaram grandes números de gestantes, também encontraram proporções de anemia ferropriva iguais ou até mesmo menores à encontrada no presente estudo. ${ }^{6,16,29-34}$ Em tais estudos as parcelas atribuídas à deficiência de ferro foram também aquém do esperado. Poucos estudos já avaliram o conteúdo medular de ferro em gestantes, utilizando pequeno número de participantes, encontrando que a maioria dos casos não foi ferrodeficiente, inclusive entre as anêmicas. ${ }^{20,35}$

Percebem-se, portanto, indícios de que a carência de ferro, a despeito de ser a deficiência nutricional mais prevalente e difundida do planeta, estaria longe de ser responsável pela grande maioria dos casos de anemia na gestação. E, por conseguinte, poderia não ser adequado utilizar a prevalência de anemia como um proxi de anemia ferropriva e dessa como um estimador de ferropenia nessa fase do ciclo vital, tanto nos países em desenvolvimento, como nos desenvolvidos.

$\mathrm{O}$ presente estudo adotou a ferritina sérica para o diagnóstico de ferropenia, tendo em vista a sua superioridade, mesmo na gravidez, em termos de sensibilidade e especificidade em relação aos outros indicadores isolados do status corporal de ferro e o caráter invasivo da biópsia de medula óssea, que seria o padrão-ouro. ${ }^{20,28,35-38} \mathrm{O}$ ponto de corte aqui admitido é sustentado pelos achados de estudos que confrontaram os valores de ferritina sérica com o conteúdo de ferro medular (dois deles em gestantes $)^{17,20,35,39,40}$ e nas distribuições dos seus valores em diversas populações de gestantes encontradas na literatura mais recente, ${ }^{13-15,31}$ assim como, na definição da OMS de depleção leve de ferro. ${ }^{1}$

No enanto, diante da baixa frequiência encontrada de ferropenia e dos níveis de ferritina acima dos sugeridos para discriminar ferropenia, sendo ainda mais elevados nas gestantes anêmicas, estabelece-se um problema conceitual intrigante, levando a conjecturas muito incipientes, tais como a influência da hemodiluição no metabolismo do ferro e o comportamento da dinâmica do ferro estocado e funcional durante a gravidez.

\section{Conclusões}

A frequiência de anemia não se comportou como um proxi de anemia ferropriva, assim como a freqüência de ferropenia não acompanhou na proporção esperada a de anemia ferropriva, independente do ponto de corte utilizado para a hemoglobina. Ademais, ser anêmica apontou para uma menor possibilidade de ferropenia.

Esses dissensos em relação aos referenciais utilizados na prática clínica e epidemiológica impõem a necessidade de estudos de base populacional, a fim de se definirem as reais prevalência e etiologia das anemias nas populações, especificamente na gestação.

\section{Referências}

1. WHO (World Health Organization). Iron deficiency anemia: assessment, prevention and control: a guide for programme managers. Geneve; 2001.

2. UNICEF (United Nations Children's Fund), WHO (World Health Organization). Prevention and control of iron deficiency anaemia in women and children. Geneve; 1999.
3. Rasmussen KM. Iron deficiency anemia: reexamining the nature and magnitude of the public health problem. Is there a causal relationship between iron deficiency or iron-deficiency anemia and weight at birth, length of gestation and perinatal mortality? J Nutr. 2001; 131: 590S-603S. 
4. Allen LH. Anemia and iron deficiency: effects on pregnancy outcome. Am J Clin Nutr. 2000; 71 (Suppl): 1280S$4 \mathrm{~S}$.

5. Scholl TO, Reilly T. Anemia, iron and pregnancy outcome. J Nutr. 2000; 130: 443-7.

6. Stotzfus RJ. Iron deficiency: global prevalence and consequences. Food Nutr Bull. 2003; 24 (4 Suppl): 99S-103S.

7. Yip R. Significance of an abnormally low or high hemoglobin concentration during pregnancy: special consideration of iron nutrition. Am J Clin Nutr. 2000; 72 (Suppl): 272S-9S.

8. Souza AI, Batista Filho M, Ferreira LOC. Alterações hematológicas e gravidez. Rev Bras Hematol Hemoter. 2002; 24 : 29-36.

9. Beaton GH. Iron needs during pregnancy: do we need to rethink our targets? Am J Clin Nutr. 2000; 72 (Suppl): 265S-71S.

10. Petraglia B, Silva LGP da, Rezende Filho J de, Netto HC, Montenegro CAB. Avaliação dos valores eritrocitários no ciclo grávido-puerperal. J Bras Ginecol. 1994; 1014: 13944.

11. Milman N, Byg KE, Agger AO. Hemoglobin and erythrocyte indices during normal pregnancy and postpartum in 206 women with and without iron supplementation. Acta Obstet Gynecol Scand. 2000; 79: 89-98.

12. Alonso RV, Fernandez VH, Perez JR, Valtueña JP. Concentración sérica de ferritina em una población normal: efecto de la edad, sexo y embarazo. Rev Clin Española. 1980; 156: 39-43

13. Kaulfer M, Casanueva E. Relation of pregnancy serum ferritin levels to hemoglobin levels throughout pregnancy. Eur J Clin Nutr. 1990; 44: 709-15.

14. van Buul EJ, Steegers EA, Jongsma HW, Eskes TK, Thomas CM, Hein PR. Haematological and biochemical profile of uncomplicated pregnancy in nulliparous women; a longitudinal study. Neth J Med. 1995; 46: 73-85.

15. Friis H, Gomo E, Kæstel P, Ndhlovu P, Nyazema N, Krarup $\mathrm{H}$, Michaelsen KF. HIV and other predictors of serum folate, serum ferritin, andhemoglobin in pregnancy: a crosssectional study in Zimbabwue. Am J Clin Nutr. 2001; 73: 1066-73.

16. Volpi E, De Grandis T, Alba E, Mangione M, Dall'Amico D, Bollati C. Variations in ferritin levels in blood during physiological pregnancy. Minerva Ginecol. 1991; 43: 38791.

17. Puolakka J. Serum ferritin as a measure of iron stores during pregnancy. Acta Obstet Gynecol Scand. 1980; 95 (Suppl): 1-31.

18. Knight EM, Spurlock BG, Edwards CH, Johnson AA, Oyemade UJ, Cole OJ, West WL, Manning M, James H, Laryea H, Westney OE, Jones S, Westney LS. Biochemical profile of African American woman during three trimesters of pregnancy and at delivery. J Nutr. 1994; 124 (6 Suppl): 943S-53S.

19. Carretti NG, Eremita AG, Paternoster D, Pellizzari P, Grella P. Iron balance in pregnancy in relation to anemia. Clin Exp Obstet Gynecol. 1992; 19: 218-21.
20. van den Broek NR, Letsky EA, Shenkin A. Iron status in pregnant women: which measurements are valid? $\mathrm{Br} \mathrm{J}$ Haematol.1998; 103: 817-24.

21. Batista Filho M, Romani SAM. Alimentação, nutrição e saúde no estado de Pernambuco. Recife; IMIP; 2002. (Série de Publicações Científicas do IMIP-Instituto Materno Infantil de Pernambuco, n. 7).

22. PAHO (Pan-American Health Organization). Flour fortification with iron, folic acid and vitamin B12. Santiago, Chile; 2003.

23. Arruda IKG. Deficiência de ferro, de folato e anemia em gestantes atendidas no Instituto Materno Infantil de Pernambuco: magnitude, fatores de risco e algumas implicações nos seus conceptos [tese doutorado]. Recife: Departamento de Nutrição do Centro de Ciências da Saúde da Universidade Federal de Pernambuco; 1997.

24. Pereira RC. Anemia em parturientes da maternidade Prof. Monteiro de Morais e peso-ao-nascer: impacto de condicionantes macro e microestruturais [dissertação mestrado]. Recife: Departamento de Nutrição, Centro de Ciências da Saúde da Universidade Federal de Pernambuco; 1997.

25. Souza AI de, Batista Filho M, Ferreira LOC, Figueirôa JN. Efetividade de três esquemas com sulfato ferroso para tratamento de anemia em gestantes. Rev Panam Salud Publica 2004; 15: 313-9.

26. Santos LMP, organizador. Bibliografia sobre deficiência de micronutrientes no Brasil: 1990-2000. Brasília, DF: OPAS ; 2002. v. 2.

27. Cardoso MA, Ferreira UM, Camargo LMA, Szarfarc SC. Anemia em população de área endêmica de malária, Rondônia (Brasil). Rev Saúde Pública. 1992; 26: 161-6.

28. Adamson JW, Longo DL. Anemia and polycythemia. In: Kasper DL, Fauci AS, Longo DL, Braunwald E, Hauser SL, Jameson JL, editors. Harrison's Principles of internal medicine. New York: McGraw-Hill; 2005. p. 329-36.

29. Scholl TO, Hediger ML, Fischer RL, Shearer JW. Anemia vs iron deficiency: increased risk of preterm delivery in a prospective study. Am J Clin Nutr. 1992; 55: 985-88.

30. Bareford D, Beevers DG, Perry IJ, Whincup PH. Predictors of ratio of placental weight to fetal weight in multiethnic community. Br Med J. 1995; 310: 436-9.

31. Tam KF, Lao TT. Hemoglobin and red cell índices correlated with serum ferritin concentration in late pregnancy. Obstet Gynecol. 1999; 93: 427-31.

32. Ronnenberg AG, Wood RJ, Wang X, Xing H, Chen C, Chen D, Guang W, Huang A, Wang L, Xu X. Preconception hemoglobin and ferritin concentrations are associated with pregnancy outcome in a prospective cohort of Chinese women. J Nutr. 2004; 134: 2586-91.

33. Alper BS, Kimber R, Reddy AK. Using ferritin levels to determine iron-deficiency anemia in pregnancy. J Fam Pract. 2000; 49: 829-32.

34. Casanova BF, Sammel MD, Macones GA. Development of a clinical prediction rule for iron deficiency anemia in pregnancy. Am J Obstet Gynecol. 2005; 193: 460-6.

35. Puolakka J, Jänne O, Pakarinen A, Vihko R. Serum ferritin in the diagnosis of anemia during pregnancy. Acta Obstet Gynecol Scand. (Suppl) 1980; 95: 57-63. 
36. Guerra-Shinohara EM, Paiva AA, Rondó PHC. Parâmetros para avaliação do estado nutricional de ferro. Rev Saúde Pública. 2000; 34: 421-6.

37. Romslo I, Haram K, Sagen N, Augensen K. Iron requirement in normal pregnancy as assessed by serum ferritin, serum transferrin saturation and erythrocyte protoporphyrin determinations. Br J Obstet Gynaecol. 1983; 90: 101-7.
38. Thompson WG. Comparison of tests for diagnosis of iron depletion in pregnancy. Am J Obstet Gynecol. 1988; 159: 1132-4.

39. Cook JD, Lipschitz DA. A clinical evaluation of ferritin as a index of iron stores. N Engl J Med. 1974; 290: 1213-6.

40. Jacobs A, Worwood M. Ferritin in serum. N Engl J Med. 1975; 298: 951-6. 